 \\ DISTRIBUTION OF THIS DOCUMENT IS UNLIMITED

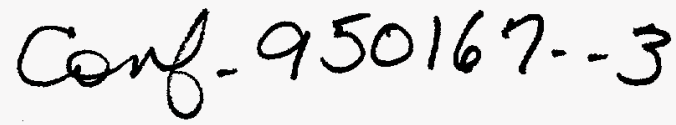

\section{Interfaces in InAsSb/InGaAs strained-layer superlattices grown by MOCVD for use in infrared emitters*}

\author{
R. M. Biefeld, D. M. Follstaedt, S. R. Kurtz, and K. C. Baucom \\ Sandia National Laboratory, Albuquerque, NM 87185-0601 USA
}

\begin{abstract}
We have prepared InAsSb/InGaAs strained-layer superlattices (SLSs) using metal-organic chemical vapor deposition (MOCVD). X-ray diffraction was used to determine lattice matching as well as composition and structure of the SLS's. The presence of an InGaAsSb interface layer was indicated by $\mathrm{x}$-ray diffraction for samples grown under non-optimized conditions. Interfacial layers were also identified with transmission electron microscopy (TEM). Two types of interfaces were observed by TEM. The different contrasts observed by TEM could be due to a difference in composition at the interfaces. The width of the $\mathrm{x}$-ray peaks can be explained by a variation of the layer thickness.
\end{abstract}

\section{Introduction}

In our recent work we prepared heterostructures with biaxially compressed, As-rich, In $A s_{1-\mathrm{x}} S b_{\mathrm{x}}$ as active regions for midwave infrared emitters[1]. InAs ${ }_{1-\mathrm{x}} S b_{\mathrm{x}} / \mathrm{In}_{1-\mathrm{x}} \mathrm{Ga} a_{\mathrm{x}} \mathrm{As}$ (x $\approx 0.1$ ) strained-layer superlattices (SLSs), nominally lattice matched to InAs were grown using metal-organic chemical vapor deposition. An SLS light-emitting diode was constructed which emitted at $3.6 \mu \mathrm{m}$ with $0.06 \%$ efficiency at $77 \mathrm{~K}$. An optically pumped, single heterostructure SLS / InPSb laser which emitted at $3.9 \mu \mathrm{m}$ with a maximum operating temperature of approximately $100 \mathrm{~K}$ was also fabricated[1]. These results indicate the potential of this system for making infrared devices and the need for improved devices able to operate in this wavelength range at higher temperature. We are continuing to explore the

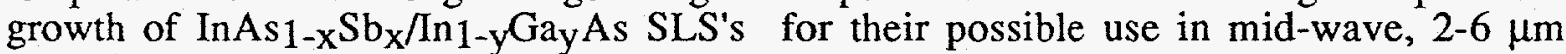
infrared optoelectronic and heterojunction devices. This system was chosen because the compositions span the 2-6 $\mu \mathrm{m}$ wavelength range and they can be grown lattice matched to InAs with type I band offsets. Our previous studies of the InAsSb ternary system have demonstrated accurate composition control through the use of a thermodynamic model $[2,3]$. We have made high quality infrared detectors in our laboratory from doped strainedlayer superlattices (SLS's) grown by MOCVD in the Sb rich end of this ternary[2,3]. We have focused our recent efforts on the growth of $\operatorname{InAs}_{1-\mathrm{X}} \mathrm{Sb}_{\mathrm{X}} / \mathrm{In}_{1-\mathrm{y}} \mathrm{Ga}_{\mathrm{y}}$ As heterostructures on InAs with emphasis on the growth and characterization of the InAsSb layers due to the importance of this material in the active devices $[1,4]$. We reported detailed growth conditions for InAs 1-x Sb $b_{X} / I_{1-y} G a_{y} A s$ SLS's and InAs 1-X Sb $b_{X}$ alloys [4]. The efficiency of emitters in the $2-6 \mu \mathrm{m}$ range is usually limited by Auger processes [1,4]. The increased electron-hole effective mass ratio of biaxially compressed InAsSb reduces the Auger 


\section{DISCLAIMER}

This report was prepared as an account of work sponsored by an agency of the United States Government. Neither the United States Government nor any agency thereof, nor any of their employees, makes any wartanty, express or implied, or assumes any legal liability or responsibility for the accuracy, completeness, or usefulness of any information, apparatus, product, or process disclosed, or represents that its use would not infringe privately owned rights. Reference herein to any specific commercial product, process, or service by trade name, trademark, manufacturer, or otherwise does not necessarily constitute or imply its endorsement, recommendation, or favoring by the United States Government or any agency thereof. The views and opinions of authors expressed herein do not necessarily state or reflect those of the United States Government or any agency thereof. 


\section{DISCLAIMER}

Portions of this document may be illegible in electronic image products. Images are produced from the best available original document. 
transition rates and increases the infrared emission. In the present work, we have examined the structure of the InAs $1-x b_{x} / I_{1-y} G_{y} A s$ SLSs in detail using $x$-ray diffraction and transmission electron diffraction. Herein we discuss the observation of an interface layer in these SLSs and possible models which can explain the observed x-ray diffraction patterns.

\section{Experimental}

This investigation was carried out in a previously described horizontal MOCVD system [5]. The sources of In, $\mathrm{Sb}$ and As were trimethylindium (TMIn), trimethylantimony (TMSb), trimethylgallium (TMG), and 100 percent arsine $\left(\mathrm{AsH}_{3}\right)$, respectively. Hydrogen was used as the carrier gas at a total flow of 8 SLM. The V/III ratio was varied from 2.7 to 10.3 over a temperature range of $475-525^{\circ} \mathrm{C}$, at total growth pressures of 200 to 660 torr and growth rates of 0.75 to $3.0 \mu \mathrm{m} / \mathrm{h}$. The group $\mathrm{V}$ molar fraction of TMSb in the vapor phase [nTMSb/(nTMSb + n AsH3)] was varied from 0.06 to 0.09 .

The growth was performed on (001) InAs substrates. InAs was cleaned by degreasing in solvents and deionized water. It was then etched for 20 to 30 seconds in a 50:1 mixture of sulfuric acid and hydrogen peroxide, rinsed with deionized water and blown dry with nitrogen.

$\mathrm{Sb}$ compositions, $\mathrm{x}$, reported for the InAs $1-\mathrm{x} S b_{\mathrm{X}}$ layers were determined by $\mathrm{x}$-ray diffraction using a $\mathrm{Cu} x$-ray source and a four crystal Si monochromator. The (004) reflection was used to measure the lattice constant normal to the growth plane and the (115) or (335) reflections were used to determine the in-plane lattice constant [5]. In this way the composition determination is corrected for partial strain relaxation by misfit dislocations. The simulations were done using the Bede RADS program.

The optical properties of these SLS's were determined by infrared photoluminescence and absorption measurements. Infrared photoluminescence was measured at $14 \mathrm{~K}$ using a double-modulation technique which provides high sensitivity, reduces sample heating, and eliminates the blackbody background from the infrared emission spectra [6].

Cross-sectional specimens of some samples were prepared for transmission electron microscopy (TEM) by cleaving along (110) and epoxying two alloy surfaces together. TEM examination was done using a Philips CM20T (200 keV) microscope. The specimens were examined in a $<110>$ direction perpendicular to the [001] growth direction. Both transmission electron diffraction (TED) patterns and TEM images were obtained.

\section{Results And Discussion}

Previous TEM experiments have shown the existence of ordering in both InAs1-X $S b_{X}$ alloys and InAs1-x Sb $/$ /n 1-yGayAs SLSs $[4,8,9]$. A high resolution transmission electron micrograph of an InAs1-x $S b_{x} / I_{1-y} \mathrm{Ga}_{y} A s$ SLS is shown in Figure 1. As can be readily seen from this micrograph, there is a distinct difference between the interfaces. Using the known growth parameters and sequencing, the In $A s{ }_{1-X} S_{x}$ layer is known to be thinner than the In $1-y G_{y} A s$ layer. It is also known from the sequencing, that the InAs1-x $S_{x}$ layer is the first layer grown in the sequence. This fact allows us to determine that the bright interfacial layer is formed when In $1-y \mathrm{Ga} A \mathrm{As}$ is grown on top of InAs $1-\mathrm{X} \mathrm{Sb}_{\mathrm{X}}$ and the dark interfacial layer is formed when $\operatorname{InAs} 1-\mathrm{x} S b_{\mathrm{X}}$ is grown on top of In $1-\mathrm{y}$ Gay As. The relative intensity of the diffraction from the layers implies that the light layer has a lower average atomic number than the dark layer. This can be explained by the presence of excess Ga and/or As in the bright layer, and excess In and/or Sb in the darker layer. The layers also appear to have a large variation in lateral thickness. The bright interfacial layer appears to 


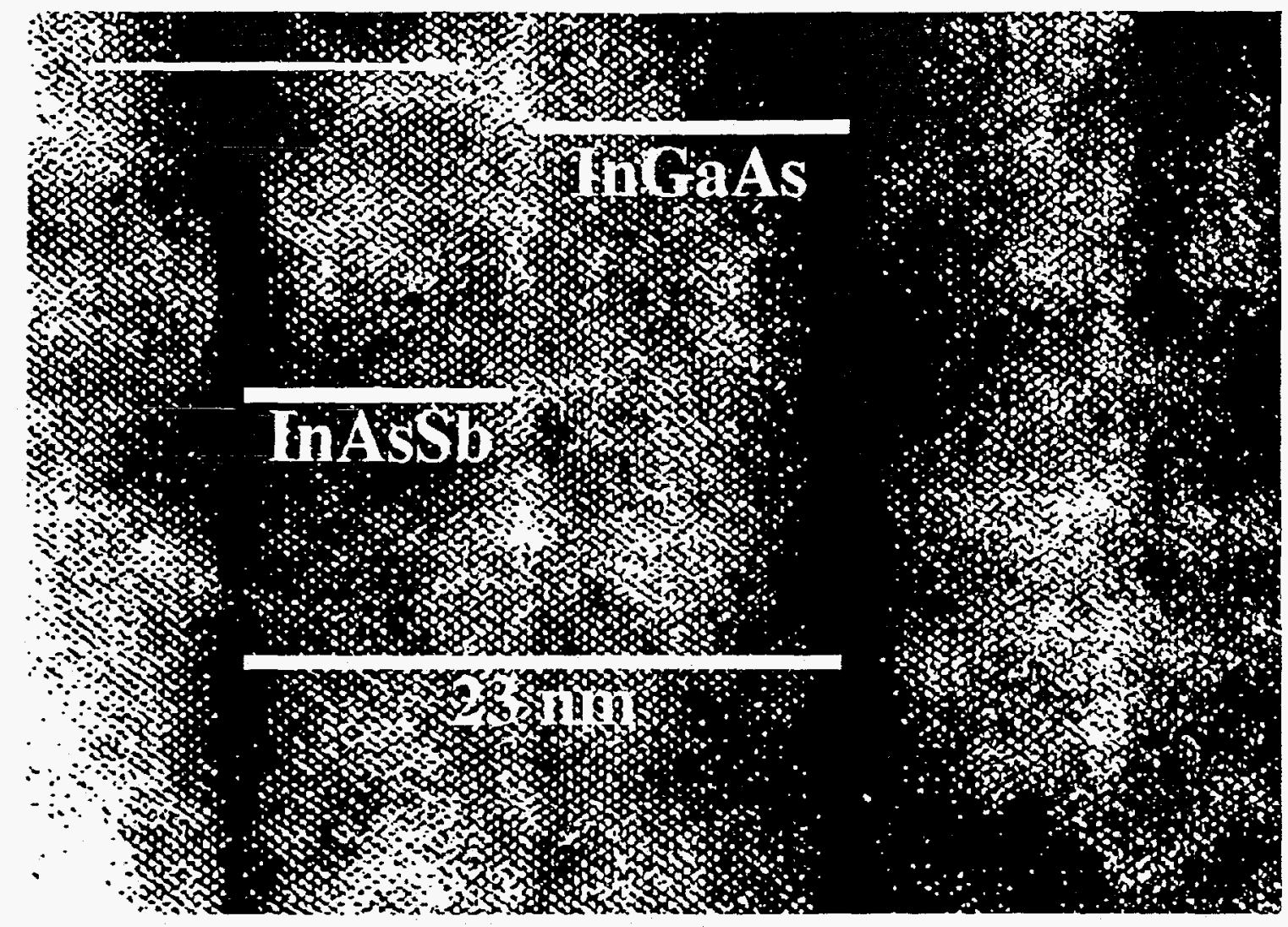

Figure 1. A high resolution lattice image showing the alternating light and dark interface regions of an InAs $1-x b_{X} / I_{1-y}$ GayAs SLS (CVD1172). The growth direction is from left to right as indicated by the arrow in the upper left hand corner.

vary in thickness from approximately 0.6 to $1.3 \mathrm{~nm}$ and the darker, thicker layer from approximately 1.0 to $1.6 \mathrm{~nm}$. This thickness variation can be used as described below to model the observed $x$-ray diffraction pattern.

Both measured and calculated $x$-ray diffraction patterns of the (004) reflection of a selected InAs1-x $\mathrm{Sb}_{\mathrm{X}} / \mathrm{In}_{1-\mathrm{y}} \mathrm{Gay}_{\mathrm{y}} \mathrm{As}$ SLS (CVD1172) grown on InAs are shown in Figure 2. The patterns show the intense InAs peak located at 0 arc seconds and the satellites due to the SLS. This sample was grown at atmospheric pressure with 30 second purges between layers with uninterrupted $\mathrm{AsH}_{3}$ flow. The calculated pattern shown in curve $\mathrm{C}$ is for an InAs $0.9 \mathrm{Sb}_{0.1} / \mathrm{In}_{0.1} \mathrm{Ga}_{0.9} \mathrm{As}_{0.9} \mathrm{Sb}_{0.1} / \mathrm{In}_{0.88} \mathrm{Ga}_{0.12} \mathrm{As} / \mathrm{In}_{0.95} \mathrm{Ga}_{0.05} \mathrm{As}_{0.8} \mathrm{Sb}_{2}$ SLS with $100 / 10 /$ $110 / 6 \AA$ layer thicknesses. This structure was chosen based on the TEM observations and the growth conditions using less In and $\mathrm{Sb}$ (more $\mathrm{Ga}$ and $\mathrm{As}$ ) for the first interface due to its lower average atomic number and more $\mathrm{In}$ and $\mathrm{Sb}$ for the second interface. The compositions of the interfaces are not a unique choice and other compositions could be used and still yield a similar pattern with small adjustments to the compositions of the thick layers.

The calculated pattern shown in curve $C$ indicates the ideal peak widths for a structure with interface layers that are repeated with no variation in thickness or composition. As one can see, the observed pattern is much broader than the ideal pattern illustrated by curve $C$. A better match to the observed pattern can be obtained by introducing thickness variations in the interfacial layers. Curve $\mathrm{B}$ was generated by using the compositions InAs $0.9 \mathrm{Sb}_{0.1} / \mathrm{In}_{0.2} \mathrm{Ga}_{0.8} \mathrm{As}_{0.9} \mathrm{Sb}_{0.1} / \mathrm{In}_{0.88} \mathrm{Ga}_{0.12} \mathrm{As} / \mathrm{In}_{0.95} \mathrm{Ga}_{0.05} \mathrm{As} 0.8 \mathrm{Sb} .2$, and varying the individual layer thicknesses while keeping the total period thickness 


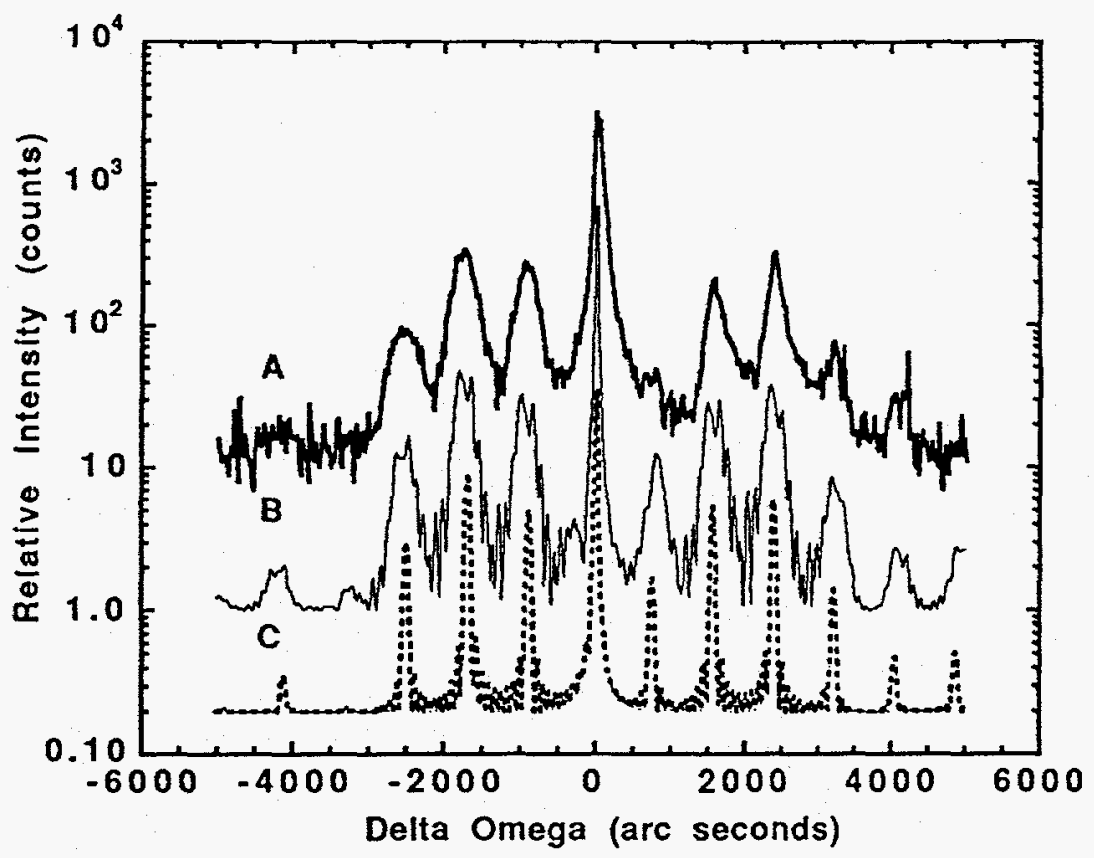

Figure 2. Curve $A$ is the observed $x$-ray diffraction pattern of the (004) reflection of CVD1172. It is compared to calculated patterns in the lower curves to illustrate the improved match when variations in the thickness of the interface layers are included in the $\mathrm{x}$-ray simulation $\mathrm{B}$ when compared to a simulation with no variations of thickness in the interface layers shown in $\mathrm{C}$.

constant. The layer thicknesses were varied from $99 / 8 / 110 / 5 \AA$ to $90 / 17 / 101 / 14 \AA$ in three steps of $2 \AA$ each and a fourth step of $3 \AA$. This modeling procedure would give the same $\mathrm{x}$ ray diffraction pattern as one in which the individual layer thicknesses were varied horizontally within the same period but keeping the same total vertical period. Again it should be emphasized that this is not a unique solution to the observed pattern but it is one that is plausible based on the observed structure from the high resolution micrograph. Other possible broadening mechanisms include a total period thickness or composition variation which are not supported by the TEM micrographs and the presence of dislocations which is indicated by TEM. The order of the layers also makes no difference to the calculated pattern. This simulated pattern, curve B, is a good match to the observed pattern, curve A, and is support for the existence of an interface layer of varying thickness as the explanation for the width observed in the x-ray diffraction pattern.

A variety of growth conditions were explored in an effort to improve the sharpness of the x-ray diffraction pattern. The optimum x-ray diffraction pattern was obtained at 200 torr with a 10 second growth interrupt at $475{ }^{\circ} \mathrm{C}$, a V/III ratio of 7 , a growth rate of 1.8 $\mu \mathrm{m} /$ hour, and no reactants flowing during the interrupt. An x-ray diffraction pattern of an SLS grown using the optimum growth technique was simulated without using interface layers and no thickness variations and a good match between the observed and calculated pattern was obtained. This improvement is due to the minimization of exposure of the InAsSb surface to $\mathrm{AsH}_{3}$ and/or As. Extended $\mathrm{AsH}_{3} / \mathrm{As}$ exposures are known to cause interface roughening in the InAs/GaSb system as well as asymmetrical interfacial layers 
$[9,10]$. The presence of $\mathrm{Ga}$ in these layers could be explained by the faster gas phase diffusion of TMGa compared to TMIn. Alternate explanations would be the roughness of the surfaces which enables mixing of $\mathrm{Ga}$ into the InAsSb layers at the interface or the diffusion of $\mathrm{Ga}$ into the InAsSb during growth.

The bandgap of the unstrained, In $\mathrm{As}_{0.9} \mathrm{Sb}_{0.1}$ alloy was determined to be approximately $270 \mathrm{meV}$ from optical studies of bulk ternary alloy and subsequent studies of SLSs and quantum wells. The accepted value for InAs $0.9 \mathrm{Sb}_{0.1}$ is $\approx 330 \mathrm{meV}$ [8]. Throughout our studies of As-rich, InAsSb $(5-50 \% \mathrm{Sb})$, the optically determined bandgap of InAsSb alloys was smaller than accepted values [5,9]. This InAsSb bandgap anomaly was observed in both MOCVD and MBE grown samples. The TED patterns for InAs $1-\mathrm{x} S \mathrm{~b}_{\mathrm{X}}$ $(x=0.07-0.14)$ alloys and an InGaAs/InAsSb SLS show bright reflections of the [110] zone pattern of the zinc-blende lattice as well as non-zinc-blende reflections at half the distance between (000) and $\{111\}$ spots. These weak reflections indicate that compositional ordering of the $\mathrm{Cu}-\mathrm{Pt}$ type is occurring on the $\{111\} \mathrm{B}$ planes of the group-V sublattice which is the same type as that which was previously observed for InAs $0.6 \mathrm{Sb} 0.4$ alloys and SLSs [8]. Compositional ordering of InAsSb should result in bandgap reduction as seen above even for low $S b$ concentrations $[7,8,11]$.

In conclusion, we have established the growth conditions for InAs $1-\mathrm{x} \mathrm{Sb}_{\mathrm{X}} /$ In 1-yGayAs SLS's that minimize the width of the $\mathrm{x}$-ray diffraction peaks. The asymmetric interfacial layers which are observed by TEM have been modeled using excess As and Ga at the interfaces. The PL peak energies of the SLS's and alloys grown under the conditions of this study are lower than those previously reported. The lower energy anomaly in these SLSs is probably due to ordering which is observed in InAs ${ }_{1-x} S b_{x}$ alloys and SLSs. We anticipate that with these improvements in material quality, we should soon realize a reduction of Auger rates and higher temperature operation of midwave emitters with biaxially compressed InAsSb.

\section{Acknowledgments}

We wish to thank J. A. Bur and M. W. Pelczynski for providing technical assistance. This work was supported by the US DOE under Contract No. DE-AC04-94AL85000.

\section{References}

[1]Kurtz S R Biefeld R M Dawson L R Baucom K C and Howard A J 1994 Appl. Phys. Lett. $64812-4$.

[2] Biefeld R M 1986 J. Crystal Growth 75 255-63.

[3] Biefeld R M Kurtz S R and Casalnuovo S A 1992 J. Crystal Growth 124 401-8.

[4] Biefeld R M Baucom K C Kurtz S R and Follstaedt D M 1994 Mat. Res. Soc. Symp. Proc., 325 493-8.

[5] Biefeld R M Hills C R and Lee S R 1988 J. Crystal Growth 91 515-26.

[6] Kurtz S R and Biefeld R M 1991 Phys. Rev. B 44 1143-9.

[7] Follstaedt D M Biefeld R M Kurtz S R and Baucom K C 1994 submitted to J. Electronic Materials.

[8] Follstaedt D M Biefeld R M Kurtz S R Dawson L R and Baucom K C to be published elsewhere in this proceedings.

[9] Chow D H Miles R H Soderstrom J R and McGill T C 1990 J. Vac. Sci. Technol. B 8 710-4.

[10] Feenstra R M Collins D A Ting D Z-Y Wang M W and McGill T C 1994 J. Vac. Sci. Technol. B 12 2592-7.

[11] Wei S-H and Zunger A. 1991 Appl. Phys. Lett. 58, 2684-6 